\title{
The Quantitation of 7 $\beta$-Hydroxy-Epiandrosterone in the Plasma and Seminal Plasma of Men With Different Degrees of Fertility
}

\author{
J. VITKU ${ }^{1}$, L. KOLATOROVA ${ }^{1}$, C. RICCO ${ }^{2}$, C. FERROUD $^{2}$, O. HENNEBERT $^{3,4}$, \\ T. SKODOVA ${ }^{1}$, J. HERACEK ${ }^{5,6}$, L. STARKA ${ }^{1}$
}

${ }^{1}$ Department of Steroids and Proteofactors, Institute of Endocrinology, Prague, Czech Republic, ${ }^{2}$ Laboratoire de Chimie Moléculaire, CMGPCE, EA7341, Conservatoire National des Arts et Métiers, Paris, France, ${ }^{3}$ Conservatoire National des Arts et Métiers, Paris, France, ${ }^{4}$ U1141 PROTECT, Inserm, Université Paris Diderot, Sorbonne Paris Cité, Hôpital Robert Debré, Paris, France, ${ }^{5}$ Department of Urology, Military University Hospital, Prague, Czech Republic, ${ }^{6}$ Department of Urology, First Faculty of Medicine, Charles University, Prague, Czech Republic

Received May 15, 2018

Accepted June 26, 2018

\section{Summary}

$7 \beta$-hydroxy-epiandrosterone $(7 \beta-\mathrm{OH}-\mathrm{EpiA})$ is an endogenous androgen metabolite that has been shown to exert neuroprotective, anti-inflammatory and anti-estrogenic effects. However, to the best of our knowledge no information is available about this androgen steroid in relation to sperm quality. We analyzed $7 \beta-\mathrm{OH}-\mathrm{EpiA}$ in plasma and seminal plasma using a newly developed isotope dilution ultra-high performance liquid chromatography - mass spectrometry method. Validation met the requirements of FDA guidelines. Levels of $7 \beta-O H-E p i A$ were measured in 191 men with different degrees of infertility. One-way analysis of variance followed by multiple comparison and correlation analysis adjusted for age, BMI and abstinence time were performed to evaluate the relationships between this steroid and sperm quality. Concentrations of $7 \beta-\mathrm{OH}-\mathrm{EpiA}$ in seminal plasma were significantly higher in severely infertile men in comparison with healthy men and slightly infertile men. The same trend was found when blood plasma was evaluated. Furthermore, plasma $7 \beta-\mathrm{OH}-\mathrm{EpiA}$ negatively correlated with sperm concentration $(-0.215 ; \mathrm{p}<0.01)$ and total count $(-0.15$; $\mathrm{p}<0.05)$. Seminal $7 \beta-\mathrm{OH}-\mathrm{EpiA}$ was negatively associated with motility $(-0.26 ; p<0.01)$, progressively motile spermatozoa $(-0.233 ; \quad p<0.01)$ and nonprogressively motile spermatozoa $(-0.188 ; p<0.05) .7 \beta-O H-E p i A$ is associated with lower sperm quality and deserves more research in that respect.

\section{Key words}

$7 \beta$-hydroxy-epiandrosterone $\bullet$ Sperm quality • Steroidogenesis • Steroid • Seminal plasma • Reproduction

\section{Corresponding author}

J. Vitku-Kubatova, Department of Steroids and Proteofactors, Institute of Endocrinology, Narodni 8, 11694 Prague 1, Czech Republic. E-mail: jvitku@endo.cz

\section{Introduction}

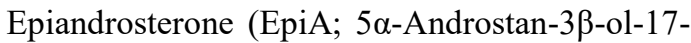
one), in the fitness world known as "prohormone", became very popular in the 1990s. It is commonly available on the black market and advertised to be a DHT booster with no estrogenic side effects such as gynecomastia or water retention. However, increased DHT levels after EpiA administration were not demonstrated in a recent experiment (Piper et al. 2017). $7 \beta$-hydroxylated EpiA (7 $\beta$-OH-EpiA; $5 \alpha$-Androstane$3 \beta, 7 \beta$-diol-17-one; Fig. 1$)$ is an endogenous androgen metabolite of EpiA and dehydroepiandrosterone (DHEA), respectively, and was reported to even have anti-estrogen effects in vitro (Niro et al. 2012).

In addition to anti-estrogenic properties, neuroprotective (Pringle et al. 2003), cytoprotective and immunomodulatory (Davidson et al. 2008, Le Mee et al. 
2008) effects have also been reported. 7ß-OH-EpiA reduced ischemia-induced neuronal damage (both in vivo and in vitro) and was suggested as a novel neuroprotective compound. It was concluded that the neuroprotective efficacy lies in the 7-hydroxylation, not in epimerization, because both 7-hydroxy epimers possess neuroprotective properties. However, $7 \beta-\mathrm{OH}-$ EpiA was protective at even lower concentrations $(10 \mathrm{nM})$ than the $7 \alpha$-epimer $(100 \mathrm{nM})$ (Pringle et al. 2003). $7 \beta-\mathrm{OH}$-EpiA also reduced neurodegeneration in an Alzheimer's disease model (Dudas et al. 2004), suggesting that it can have neuroprotective effects in acute as well as chronic diseases. With its antiinflammatory properties and ability to modulate arachidonic acid metabolism, it was also suggested as an alternative approach in the treatment of inflammatory bowel disease (Hennebert et al. 2008).

EpiA can be formed by 2 mechanisms: 1) the classic pathway from androst-4-ene-3,17-dione, or 2) indirectly through a back-door pathway from isopregnanolone (3 $\beta$-hydroxy-5 $\alpha$-pregnan-20-one) by CYP17A1 (17 $\alpha$-hydroxylase, 17.20 lyase) (Vankova et al. 2016). 7 $\alpha$-hydroxylation of EpiA is catalyzed by CYP7B1 (oxysterol and steroid 7alpha hydroxylase) (Kim et al. 2004, Starka 2017). NADP(H) dependent $11 \beta$-hydroxysteroid dehydrogenase type 1 is then responsible for the conversion of $7 \alpha-\mathrm{OH}-\mathrm{EpiA}$ to $7 \beta-\mathrm{OH}-$ EpiA (Hennebert et al. 2007). Oxygenation of EpiA occurs mainly in the intestine, brain and especially liver (reviewed in El Kihel 2012).

The information about $7 \beta-O H-E p i A$ and reproductive health is scarce. 7-hydroxylated derivatives of DHEA have been already found in seminal plasma and their possible immunomodulatory and antioxidative properties in this matrix were discussed (Hampl et al. 2003, Pohanka et al. 2002). With respect to immunomodulatory effects of $7 \beta-\mathrm{OH}-\mathrm{EpiA}$, its presence in seminal plasma is of interest.

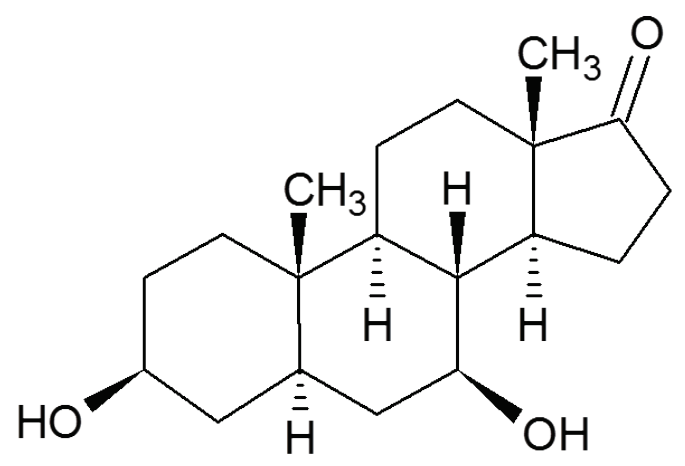

Fig. 1. Molecular structure of $7 \beta$-hydroxy-epiandrosterone.
To the best of our knowledge no information is available on plasma or seminal plasma levels of $73-\mathrm{OH}-$ EpiA in humans. Therefore, we aimed to develop a sensitive and accurate method to measure $7 \beta-\mathrm{OH}$-EpiA in both fluids. Furthermore, we determined the relationships between $7 \beta$-OH-EpiA and sperm quality assessed by spermiogram values in men with different degrees of fertility.

\section{Methods}

\section{Study group}

The studied cohort consisted of 191 Czech men (all Caucasian) attending the Pronatal Centre of Assisted Reproduction (Prague, Czech Republic). Our previous study provides a detailed overview of the characteristics of the study population (Vitku et al. 2016). All subjects underwent an ejaculate examination according to the World Health Organization (WHO) 2010 criteria, and based on these results they were divided into 4 groups: first group consisted of normospermic men, the second group comprised oligospermic, asthenospermic or oligoasthenospermic men, the third group included teratospermic, oligoasthenoteratospermic and asthenoteratospermic men, while the fourth group consisted of azoospermic men. We termed these groups: 1) healthy men, and 2) slightly, 3) moderately and 4) severely infertile men. Table 1 shows the basic characteristics of these groups.

The mean age $( \pm \mathrm{SD})$ of all participants was $35.8 \pm 5.6$ years and mean BMI value was $27.2 \pm 3.6 \mathrm{~kg} / \mathrm{m}^{2}$. $55 \%$ of men in our study were overweight (BMI 25-30) and $20 \%$ were obese (BMI>30). Neither BMI values, nor age, nor abstinence time significantly differed among the groups of men studied (Table 1, Vitku et al. 2016).

The study was performed in accordance with the Declaration of Helsinki (2000) of the World Medical Association. The protocol was approved by the Ethical Committee of the Institute of Endocrinology. Informed and written consent with the use of biological materials were obtained from all subjects before participating in the project.

\section{Chemicals and reagents}

The steroids $7 \beta-O H-E p i A$ and D2-7 $\beta-O H-E p i A$ were synthesized in Laboratoire de Chimie moléculaire, Conservatoire National des Arts et Métiers as previously described (Ferroud et al. 2012, Ricco et al. 2011). 2-hydrazinopyridine, ammonium formate and trifluoroacetic acid were from Sigma-Aldrich (St. Louis, 

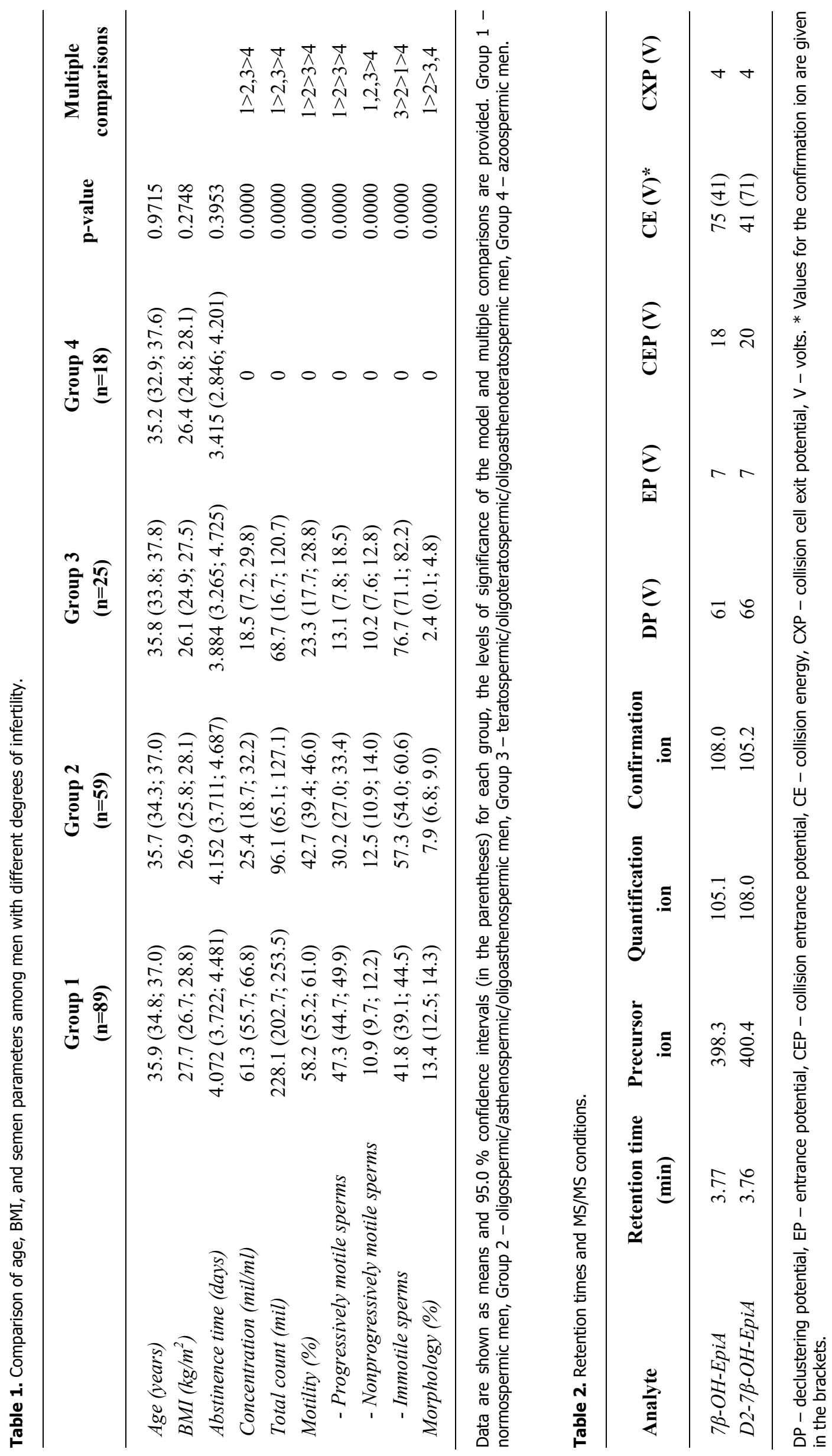


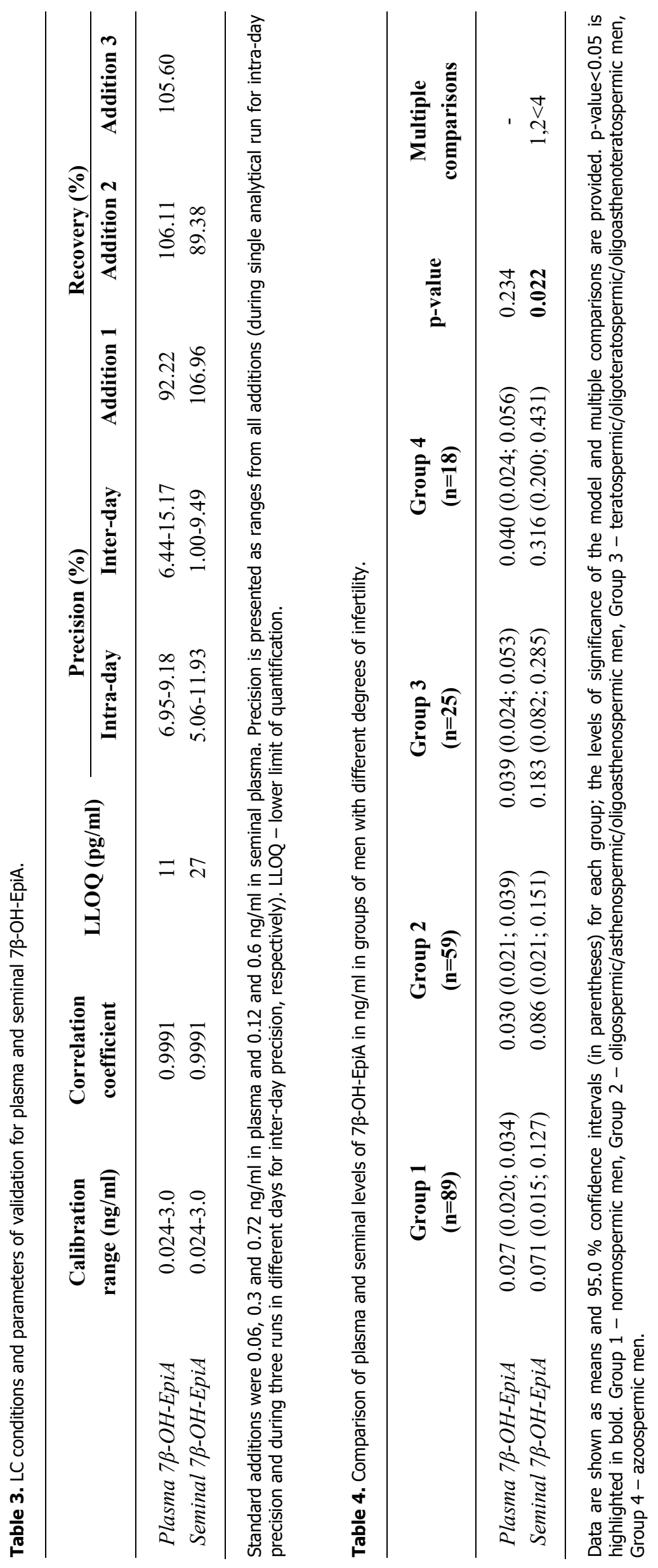


<smiles>C[C@]12CC[C@@H]3[C@H]([C@@H]1CCC2=O)[C@H](O)C[C@@H]1C[C@H](O)CC[C@@]13C</smiles>

Formula Weight $\quad=306.4397$ 7 beta-hydroxy-epiandrosterone

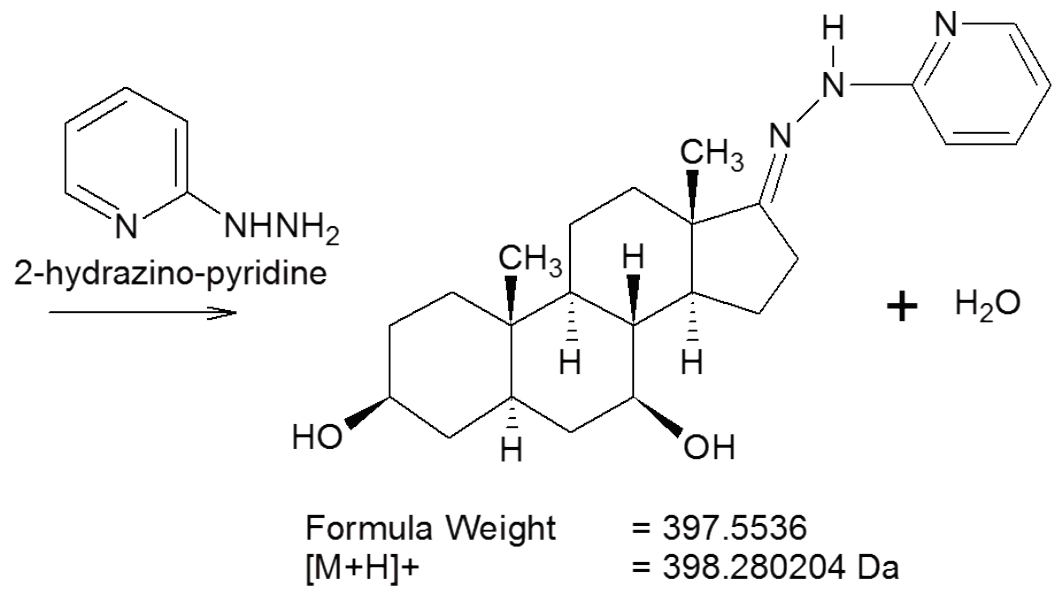

Fig. 2. Derivatization reaction of $7 \beta-O H-E p i A$ with 2-hydrazinopyridine.

MO, USA). Methanol and water for chromatography were of HPLC grade and were purchased from Merck (Darmstadt, Germany). Diethyl ether was obtained from Lach-Ner, s.r.o. (Neratovice, Czech Republic). The physiological solution ( $0.9 \%$ sodium chloride) was from B. Braun (Melsungen AG, Germany).

\section{Sample preparation}

Determination of $7 \beta-\mathrm{OH}-\mathrm{EpiA}$ in plasma and seminal plasma was added to an existing method that has already been published (Sosvorova et al. 2015, Vitku et al. 2016). In brief, a sample of plasma $(500 \mu \mathrm{l})$ or seminal plasma $(1,000 \mu \mathrm{l})$ was spiked with $10 \mu \mathrm{l}$ of an internal standard (IS) mixture (deuterated analogues of 7 $\beta$-OH-EpiA, pregnenolone, 17-OH-pregnenolone, dehydroepiandrosterone -DHEA, 7 $\alpha$-OH-DHEA, 7-oxoDHEA, cortisol, cortisone, testosterone, androstendione, dihydrotestosterone) and diluted with $500 \mu \mathrm{l}$ of physiological solution. Samples were shaken, and a liquid-liquid extraction using diethyl ether ( $3 \mathrm{ml}, 1 \mathrm{~min})$ was performed. Dry residues were derivatized by $100 \mu \mathrm{l}$ of 2-hydrazinopyridine (Fig. 2) in methanol with the addition of trifluoroacetic acid $(1 \mathrm{mg}$ : $5 \mathrm{ml}$ : $1.63 \mu \mathrm{l})$ according to Higashi et al. (2007). The samples were again shortly shaken and then sonicated for $15 \mathrm{~min}$. After evaporating under a gentle stream of nitrogen, samples were redissolved in $100 \mu 1$ of $5 \mathrm{mM}$ ammonium formate in $60 \%$ methanol, of which $50 \mu 1$ was injected into the liquid chromatograph.

Liquid chromatography/mass spectrometry (LC-MS/MS) of steroids

An ultra-high pressure liquid chromatography (UHPLC) Eksigent ultraLC 110 system (Redwood City,
CA, USA) equipped with a Kinetex C18 column (100 x $3.0 \mathrm{~mm}, 2.6 \mu \mathrm{m}$; Phenomenex, Torrance, CA, USA) and Security Guard ULTRA cartridge system (UHPLC C18 for $3 \mathrm{~mm}$ ID column; Phenomenex, Torrance, CA, USA) was used for analyte separation. Column temperature was maintained at $50{ }^{\circ} \mathrm{C}$ and separation was carried out at a flow rate of $0.75 \mathrm{ml} / \mathrm{min}$. Detection of the analytes was performed on an API 3200 mass spectrometer (Sciex, Concord, Canada) with an electrospray ionization (ESI) probe operating in positive mode. Retention times and transitions with optimized conditions for MS for 7 3 -OH-EpiA and D2-7 $\beta-O H-E p i A$ are summarized in Table 2. Example of the chromatogram obtained from the real sample (concentration of $7 \beta-\mathrm{OH}-\mathrm{EpiA} 2.64 \mathrm{ng} / \mathrm{ml}$ ) is provided in Figure 3. Analyst 1.6 software was used for system control and data evaluation. More information about the LC-MS/MS conditions can be found in the study of Sosvorova et al. (2015). Calibration ranges, correlation coefficients of calibration curves and lower limits of quantifications (LLOQs) are provided in Table 3.

\section{Validation}

Validation parameters met the criteria of the FDA Guidance for Industry (Food nad Drug Administration 2001) in terms of selectivity, accuracy, precision, recovery, calibration curve, and stability of analyte in spiked samples. Acceptable selectivity was defined as the absence of any detectable SRM LC-MS/MS ion currents at the retention time regions of each analyte and its deuterated standards in charcoal treated plasma samples. Samples were tested for further interference during prevalidation phase. Validation experiments included standard additions of $7 \beta$-OH-EpiA 
in six replicates. Four different concentrations were measured in the plasma matrix (pooled plasma + 3 additions), whereas only 3 different concentrations where measured in seminal plasma (pooled seminal plasma +2 additions) due to the limited amount of seminal plasma matrix. Accuracy, precision and recovery were then determined and are shown in Table 3. The spiked concentrations were $0.06,0.3$ and $0.72 \mathrm{ng} / \mathrm{ml}$ in plasma and 0.12 and $0.6 \mathrm{ng} / \mathrm{ml}$ in seminal plasma. Stability tests and matrix effects were evaluated as well, with satisfactory results. More details on performing validation tests can be found in Vitku et al. (2016).

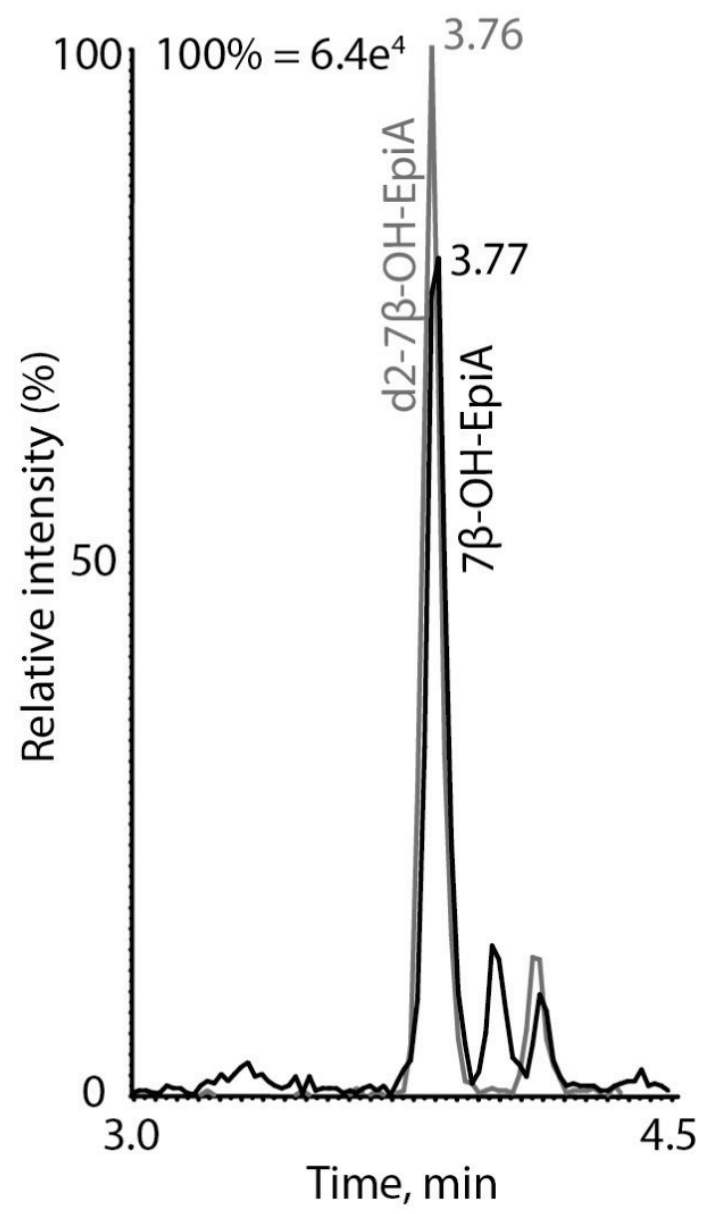

Fig. 3. Chromatogram of $7 \beta-O H-E p i A$ in plasma. Measured concentration was $2.64 \mathrm{ng} / \mathrm{ml}$.

\section{Statistical analysis}

Data that were below the limit of detection were replaced by LOD $/ \sqrt{ } 2$ (Hornung and Reed 1990). All data were subsequently transformed by Box-Cox transformation due to non-Gaussian distribution and heteroscedasticity of variables. One-way analysis of variance (ANOVA) followed by least square difference multiple comparisons was used to evaluate differences between groups of variously infertile men. Partial correlations adjusted for age, BMI and abstinence time were used for assessing relationships between levels of $7 \beta-\mathrm{OH}-\mathrm{EpiA}$ and parameters of sperm quality. The statistical software Statgraphics Centurion XVI from Statpoint Inc. (Warrenton, VA, USA) was used for data transformations, ANOVA testing and multiple comparisons. Partial correlations analyses were performed using NCSS 2007 (Kaysville, UT, USA).

\section{Results}

We analyzed 191 samples of plasma and seminal plasma. $7 \beta-\mathrm{OH}-\mathrm{EpiA}$ was detected in $65 \%$ of plasma samples and $84 \%$ of seminal samples. Differences between plasma and seminal levels of $7 \beta-O H-E p i A$ in 4 groups of men with various degree of infertility are given in Table 4. Seminal plasma showed a mild accumulation of this steroid in comparison with blood plasma. Furthermore, $7 \beta-\mathrm{OH}-\mathrm{EpiA}$ concentrations in seminal plasma increase from healthy men towards severely infertile men. The same trend was also observed for $7 \beta-O H-E p i A$ levels in plasma.

Partial correlations adjusted for age, BMI and abstinence time between sperm parameters and $7 \beta-\mathrm{OH}-\mathrm{EpiA}$ in both body fluids are given in Table 5. Plasma $7 \beta-\mathrm{OH}-\mathrm{EpiA}$ negatively correlated with sperm concentration and total count, while $7 \beta-\mathrm{OH}-\mathrm{EpiA}$ in seminal plasma was negatively associated with motility including progressively motile spermatozoa and nonprogressively motile spermatozoa. Taken together, these observations indicated negative associations of this steroid with sperm quality.

To be complete, we investigated the relationships between plasma and seminal $7 \beta-O H-E p i A$ and the following other steroids measured in our previous study (Vitku et al. 2016) in the same cohort pregnenolone, 17-hydroxy-pregnenolone, cortisol, cortisone, DHEA, 7 $\alpha$-hydroxy-DHEA, 7 $\beta$-hydroxyDHEA, 7-oxo-DHEA, testosterone, androstenedione, dihydrotestosterone, $17 \beta$-estradiol, estrone and estriol. No correlations except for a positive correlation of $7 \beta-O H-E p i A$ with DHEA in seminal plasma $(r=0.227$; $\mathrm{p}=0.009$ ) were found. 
Table 5. Partial correlations adjusted for age, BMI and abstinence time between sperm parameters and 7ß-OH-EpiA in both body fluids.

\begin{tabular}{|c|c|c|c|c|}
\hline \multirow{2}{*}{ Sperm parameters } & \multicolumn{2}{|c|}{ Plasma 7ß-OH-EpiA } & \multicolumn{2}{|c|}{ Seminal $7 \beta-O H-E p i A$} \\
\hline & $\mathbf{r}$ & p-value & $\mathbf{r}$ & p-value \\
\hline Concentration (mil/ml) & -0.215 & 0.004 & -0.045 & 0.611 \\
\hline Total count & -0.150 & 0.046 & -0.112 & 0.205 \\
\hline Motility & -0.035 & 0.643 & -0.260 & 0.003 \\
\hline - Progressively motile spermatozoa & -0.024 & 0.754 & -0.233 & 0.008 \\
\hline - Nonprogressively motile spermatozoa & -0.144 & 0.055 & -0.188 & 0.032 \\
\hline - Immotile spermatozoa & -0.149 & 0.048 & -0.022 & 0.805 \\
\hline Morphology & -0.145 & 0.067 & -0.105 & 0.262 \\
\hline
\end{tabular}

The correlation coefficient of partial correlation $r$ is a measure of the strength between variables and the $p$-value shows statistical significance. $p$-value $<0.05$ are highlighted in bold.

\section{Discussion}

To the best of our knowledge, this is the first study to determine $7 \beta-\mathrm{OH}-\mathrm{EpiA}$ concentrations in human body fluids. Derivatization by 2-hydrazinopyridine in the method enhanced the sensitivity and enabled us to analyze this androgen metabolite in the $\mathrm{pg} / \mathrm{ml}$ order of magnitude, which are the concentrations occurring in plasma and seminal plasma. 2-hydrazinopyridine has also been previously used for derivatization of oxosteroids with satisfactory results (Higashi et al. 2007, Lionetto et al. 2017).

The concentrations of $7 \beta-\mathrm{OH}-\mathrm{EpiA}$ were found to range from LLOQ- $0.167 \mathrm{ng} / \mathrm{ml} \quad(0.549 \mathrm{nmol} / \mathrm{l})$ in normospermic male plasma and LLOQ-0.358 ng/ml $(1.176 \mathrm{nmol} / \mathrm{l})$ in seminal plasma. In comparison with other 7-hydroxylated C19 steroids, the plasma concentrations were within the same order of magnitude or slightly lower (Hampl et al. 2003, Macova et al. 2014, Starka et al. 2006, Vitku et al. 2017). Concentrations of $7 \beta-O H-D H E A$ have been found to be lower in seminal plasma than in plasma (Vitku et al. 2016), in contrast to $7 \beta-\mathrm{OH}-\mathrm{EpiA}$ where an accumulation in seminal plasma was observed.

The most striking differences were found between seminal concentrations of $7 \beta-\mathrm{OH}-\mathrm{EpiA}$ in healthy men and severely infertile men; however, the whole steroid hormonal balance seems to be disrupted in men with impaired spermatogenesis. Seminal T (Zalata et al. 2014, Zhang et al. 2010), DHT (Vitku et al. 2016, Zalata et al. 1995) and androstenedione (Zalata et al. 2014) levels have been found to decrease towards infertile men. On the other hand, seminal concentrations of 17 $\alpha$-hydroxy-progesterone (Zalata et al. 2014), progesterone (Zalata et al. 2014), DHEA (Vitku et al.
2016), $5 \alpha$-androstane-3 $\alpha, 17 \beta$-diol (Zalata et al. 2014), E2 (Bujan et al. 1993, Luboshitzky et al. 2002, Vitku et al. 2016, Vitku et al. 2015, Zalata et al. 2014, Zhang et al. 2010), other estrogens (Vitku et al. 2016), as well as $7 \beta-O H-E p i A$ have been found to increase.

These are preliminary data and the molecular mechanism of $7 \beta-\mathrm{OH}-$ EpiA action in semen is unknown so far. We could hypothesize that the steroidogenic pathway towards DHT is supressed on behalf of the production of E2 and 7 $\beta-\mathrm{OH}-\mathrm{EpiA}$. The elevated levels of the cytoprotective $7 \beta-\mathrm{OH}$-EpiA in infertile men could be a compensatory mechanism towards an improvement of sperm quality.

\section{Conclusion}

Many steroids circulate in the human body, some of which have biological activity, while others are precursors or metabolites (without biological activity). The functions of many of these other steroids including $7 \beta-\mathrm{OH}-\mathrm{EpiA}$ are frequently insufficiently explored. Here we contribute information on the concentration ranges of this steroid in healthy men compared to men with different degrees of fertility. The data revealed a negative relationship between $7 \beta-\mathrm{OH}-\mathrm{EpiA}$ and sperm parameters, and may help to better understand changes in the steroid pathway in relation to partial or complete infertility.

\section{Conflict of Interest}

There is no conflict of interest.

\section{Acknowledgements}

This work was supported by Ministry of Health of the Czech Republic (MH CZ), grant nr. NV17-30528A and MH CZ DRO (Institute of Endocrinology - EÚ, 00023761). 


\section{References}

BUJAN L, MIEUSSET R, AUDRAN F, LUMBROSO S, SULTAN C: Increased oestradiol level in seminal plasma in infertile men. Hum Reprod 8: 74-77, 1993.

DAVIDSON J, WULFERT E, ROTONDO D: 7beta-hydroxy-epiandrosterone modulation of 15-deoxy-delta12,14prostaglandin $\mathrm{J} 2$, prostaglandin D2 and prostaglandin $\mathrm{E} 2$ production from human mononuclear cells. $J$ Steroid Biochem Mol Biol 112: 220-227, 2008.

DUDAS B, HANIN I, ROSE M, WULFERT E: Protection against inflammatory neurodegeneration and glial cell death by 7beta-hydroxy epiandrosterone, a novel neurosteroid. Neurobiol Dis 15: 262-268, 2004.

EL KIHEL L: Oxidative metabolism of dehydroepiandrosterone (DHEA) and biologically active oxygenated metabolites of DHEA and epiandrosterone (EpiA) - recent reports. Steroids 77: 10-26, 2012.

FERROUD C, REVIAL G, MORFIN R: Chemical and biochemical approaches to the production of 7-hydroxylated C19-steroids. Horm Mol Biol Clin Investig 10: 293-299, 2012.

FOOD AND DRUG ADMINISTRATION: Bioanalytical Method Validation, Guidance for Industry, 2001 [Retrieved 25.1.2018]; Available from: http://www.fda.gov/downloads/drugs/guidancecomplianceregulatoryinformation/ guidances/ucm070107.pdf

HAMPL R, POHANKA M, HILL M, STARKA L: The content of four immunomodulatory steroids and major androgens in human semen. J Steroid Biochem Mol Biol 84: 307-316, 2003.

HENNEBERT O, PERNELLE C, FERROUD C, MORFIN R: 7alpha- and 7beta-hydroxy-epiandrosterone as substrates and inhibitors for the human 11beta-hydroxysteroid dehydrogenase type 1. J Steroid Biochem Mol Biol 105: 159-165, 2007.

HENNEBERT O, PELISSIER MA, LE MEE S, WULFERT E, MORFIN R: Anti-inflammatory effects and changes in prostaglandin patterns induced by 7beta-hydroxy-epiandrosterone in rats with colitis. J Steroid Biochem Mol Biol 110: 255-262, 2008.

HIGASHI T, NISHIO T, HAYASHI N, SHIMADA K: Alternative procedure for charged derivatization to enhance detection responses of steroids in electrospray ionization-MS. Chem Pharm Bull (Tokyo) 55: 662-665, 2007.

HORNUNG RW, REED LD: Estimation of Average Concentration in the Presence of Nondetectable Values. Appl Occup Environ Hyg 5: 46-51, 1990.

KIM SB, CHALBOT S, POMPON D, JO DH, MORFIN R: The human cytochrome P4507B1: catalytic activity studies. J Steroid Biochem Mol Biol 92: 383-389, 2004.

LE MEE S, HENNEBERT O, FERREC C, WULFERT E, MORFIN R: 7beta-hydroxy-epiandrosterone-mediated regulation of the prostaglandin synthesis pathway in human peripheral blood monocytes. Steroids 73: 1148-1159, 2008.

LIONETTO L, DE ANDRES F, CAPI M, CURTO M, SABATO D, SIMMACO M, BOSSU P, SACCHINELLI E, ORFEI MD, PIRAS F, BANAJ N, SPALLETTA G: LC-MS/MS simultaneous analysis of allopregnanolone, epiallopregnanolone, pregnanolone, dehydroepiandrosterone and dehydroepiandrosterone 3-sulfate in human plasma. Bioanalysis 9: 527-539, 2017.

LUBOSHITZKY R, KAPLAN-ZVERLING M, SHEN-ORR Z, NAVE R, HERER P: Seminal plasma androgen/oestrogen balance in infertile men. Int J Androl 25: 345-351, 2002.

MACOVA L, BICIKOVA M, ZAMRAZILOVA H, HILL M, KAZIHNITKOVA H, SEDLACKOVA B, STARKA L: Reduced levels of circulating 7alpha-hydroxy-dehydroepiandrosterone in treated adolescent obese patients. Physiol Res 63: 95-101, 2014.

NIRO S, PEREIRA E, PÉLISSIER M-A, MORFIN R, HENNEBERT O: The DHEA metabolite 7beta-hydroxyepiandrosterone exerts anti-estrogenic effects on breast cancer cell lines. Steroids 77: 542-551, 2012.

PIPER T, PUTZ M, SCHANZER W, POP V, MCLEOD MD, UDUWELA DR, STEVENSON BJ, THEVIS M: Epiandrosterone sulfate prolongs the detectability of testosterone, 4-androstenedione, and dihydrotestosterone misuse by means of carbon isotope ratio mass spectrometry. Drug Test Anal 9: 1695-1703, 2017.

POHANKA M, HAMPL R, STERZL I, STARKA L: Steroid hormones in human semen with particular respect to dehydroepiandrosterone and its immunomodulatory metabolites. Endocr Regul 36: 79-86, 2002. 
PRINGLE AK, SCHMIDT W, DEANS JK, WULFERT E, REYMANN KG, SUNDSTROM LE: 7-hydroxylated epiandrosterone (7-OH-EPIA) reduces ischaemia-induced neuronal damage both in vivo and in vitro. Eur $J$ Neurosci 18: 117-124, 2003.

RICCO C, REVIAL G, FERROUD C, HENNEBERT O, MORFIN R: Synthesis of 7beta-hydroxy-epiandrosterone. Steroids 76: 28-30, 2011.

SOSVOROVA L, VITKU J, CHLUPACOVA T, MOHAPL M, HAMPL R: Determination of seven selected neuro- and immunomodulatory steroids in human cerebrospinal fluid and plasma using LC-MS/MS. Steroids 98: 1-8, 2015.

STARKA L: The origin of 7a-hydroxy-dehydroepiandrosterone and its physiological role: a history of discoveries. Physiol Res 66 (Suppl 3): S285-S294, 2017.

STARKA L, HILL M, HAVLIKOVA H, KANCHEVA L, SOBOTKA V: Circulating neuroactive C21- and C19-steroids in young men before and after ejaculation. Physiol Res 55: 429-436, 2006.

VANKOVA M, HILL M, VELIKOVA M, VCELAK J, VACINOVA G, DVORAKOVA K, LUKASOVA P, VEJRAZKOVA D, RUSINA R, HOLMEROVA I, JAROLIMOVA E, VANKOVA H, KANCHEVA R, BENDLOVA B, STARKA L: Preliminary evidence of altered steroidogenesis in women with Alzheimer's disease: have the patients "OLDER" adrenal zona reticularis? J Steroid Biochem Mol Biol 158: 157-177, 2016.

VITKU J, SOSVOROVA L, CHLUPACOVA T, HAMPL R, HILL M, SOBOTKA V, HERACEK J, BICIKOVA M, STARKA L: Differences in bisphenol A and estrogen levels in the plasma and seminal plasma of men with different degrees of infertility. Physiol Res 64 (Suppl 2): S303-S311, 2015.

VITKU J, HERACEK J, SOSVOROVA L, HAMPL R, CHLUPACOVA T, HILL M, SOBOTKA V, BICIKOVA M, STARKA L: Associations of bisphenol A and polychlorinated biphenyls with spermatogenesis and steroidogenesis in two biological fluids from men attending an infertility clinic. Environ Int 89-90: 166-173, 2016.

VITKU J, KOLATOROVA L, HAMPL R: Occurrence and reproductive roles of hormones in seminal plasma. Basic Clin Androl 27: 19, 2017.

ZALATA A, HAFEZ T, VERDONCK L, VERMEULEN L, COMHAIRE F: Androgens in seminal plasma: markers of the surface epithelium of the male reproductive tract. Int J Androl 18: 271-277, 1995.

ZALATA A, EL-MOGY M, ABDEL-KHABIR A, EL-BAYOUMY Y, EL-BAZ M, MOSTAFA T: Seminal androgens, oestradiol and progesterone in oligoasthenoteratozoospermic men with varicocele. Andrologia 46: 761-765, 2014.

ZHANG Q, BAI Q, YUAN Y, LIU P, QIAO J: Assessment of seminal estradiol and testosterone levels as predictors of human spermatogenesis. J Androl 31: 215-220, 2010. 